\title{
Aluminum Combustion Thermophotovoltaic for High Energy Density, Long Duration Power Applications
}

This paper was downloaded from TechRxiv (https://www.techrxiv.org).

\section{LICENSE}

CC BY 4.0

SUBMISSION DATE / POSTED DATE

$18-01-2022$ / 24-01-2022

\section{CITATION}

McConohy, Geoff (2022): Aluminum Combustion Thermophotovoltaic for High Energy Density, Long Duration Power Applications. TechRxiv. Preprint. https://doi.org/10.36227/techrxiv.18583769.v1

$\mathrm{DOI}$ 


\section{Aluminum Combustion Thermophotovoltaic for High Energy Density, Long Duration Power Applications Geoff McConohy Stanford University-Department of Materials Science and Engineering January 2022}

At first glance, it may appear that low carbon transportation is a solved problem, due to the proliferation of low-cost lithium-ion batteries. However, in the case of long-distance transportation, it may be the case that rechargeable batteries do not achieve the high energy density or low cost for applications such as heavy machinery, long distance trucking, or intercontinental shipping.

Hydrogen fuel cells have been the power system of the future for many decades, leading this to be the obvious choice for long range transport. However, despite decades of R\&D, hydrogen fuel cells have been deployed in niche applications. Many of these issues are in infrastructure, economics, and policy, but some are technical: the volumetric energy density of even liquid hydrogen is only modest (ignoring liquification energy, liquid hydrogen is $\sim 8 \mathrm{MJ} / \mathrm{L}$ compared to $38 \mathrm{MJ} / \mathrm{L}$ for octane combustion), few/any alternatives to precious metal catalysts have been deployed, and there is unfavorable scaling (linear) for the weight and volume of fuel cells with respect to rated power.

For large systems it is likely that combustion-based power generation will be optimal, due to the high-power densities enabled by high temperature reactions, favorable power-size scaling of engines, and the high energy density of oxidation reactions. However, if we restrict our fuel choice to those without any carbon emissions, then there are exceedingly few choices remaining. Ammonia is a promising choice, but the cryogenic or high-pressure storage of a highly toxic gas might be an issue for some applications.

One neglected option for fuels is the oxidation of metals. The idea is that metals can be used in a zero-carbon fuel cycle by combusting the meatal in an engine, and then re-smelting the resulting oxide back to metal. Metals as fuels have several advantages, including high energy density, earth abundance, carbon free combustion, and large-scale production. Except for a small number of academic papers, and one iron combustion pilot project in Europe [1-3], this concept has received little attention from the energy technology development sphere. Of the metals which are candidates for use as a fuel, aluminum is one of the most attractive options because of its direct production using electrochemical methods [2]. This is done on a massive scale, as the largest non-ferrous commodity metal produced [4]. Currently, aluminum production also involves large amounts of CO2 emissions. But recently, carbon-free anodes have been deployed and will continue to gain market share in the future [5]. In addition, the high energy density (61 MJ/L, normalized by aluminum oxide volume, 80 $\mathrm{MJ} / \mathrm{L}$ normalized by aluminum metal) and stability of aluminum allow for simple transport and storage.

Why not aluminum batteries?: Electrochemical systems have many inherent disadvantages for metal-oxygen reactions. One particularly difficult problem is the low ionic and electronic conductivity of the oxide products which form upon discharge. This results in systems which cannot be re-charged, rendering aluminum useful only in primary cells. Single use batteries are likely prohibitively expensive to use as a source of power, due to the complex manufacturing of battery systems. Even if primary batteries were to be used, the aluminum electrode needs to be constructed of very high purity aluminum to avoid corrosion with aqueous electrolytes, leading to high costs [6].

Challenges: One large issue with the use of aluminum as a fuel is the apparatus required to burn it. All previous research on the combustion of aluminum requires that the aluminum be in powdered form to allow for fast enough reaction rates to sustain the flame [7-8]. Powdered aluminum is much more flammable than the bulk form, and has raised safety concerns by others in the field [9]. The other issue is that the products of metal combustion are solids, not gasses, making 
the use of internal combustion piston engines or turbines infeasible. In conventional mechanical engines, the combustion of solid fuels requires the use of a boiler and steam turbines, which would dramatically increase the size of the overall system, and also decrease efficiency compared to other engines.

Photothermalvoltaics: With the desirable mechanical engines likely infeasible for metal combustion, a new approach is needed. Interestingly, the combustion of aluminum occurs at extremely high temperatures ( $>2500 \mathrm{~K}$ based on fitting of IR spectral data [7]). This makes the fuel an attractive candidate for thermophotovoltaic (TPV) systems which convert heat/light into electricity directly by using photovoltaic (PV) cells. TPV systems are unique compared to solar PV because the heat source can be completely contained, surrounded by PV cells and reflectors, which enable a high number of low energy photons to be recycled, and increased in energy to above the band gap of the PV cell, significantly increasing efficiency. TPV systems have been shown to reach $30 \%$ spectral efficiency at $1500 \mathrm{~K}$ in lab scale tests, and can likely reach $50 \%$ with reasonable improvements in reflector, chamber, and PV cell design [10]. This is comparable to some of the best mechanical combustion engines. Other groups have achieved $34 \%$ experimental efficiency at $1700 \mathrm{~K}$ as well [11]. With a flame temperature of $2500 \mathrm{~K}$, the practical efficiency limit may be even higher for an aluminum combustion system. In addition to efficiency, TPV systems have no moving parts which the solid combustion products will interfere with, enabling the heat engine to function without mechanical failure. However, it is unclear how the resulting oxide particles will interfere with a PV cell operation. For example, the oxide particles may stick to the PV cells, blocking incoming light, and reducing power output.

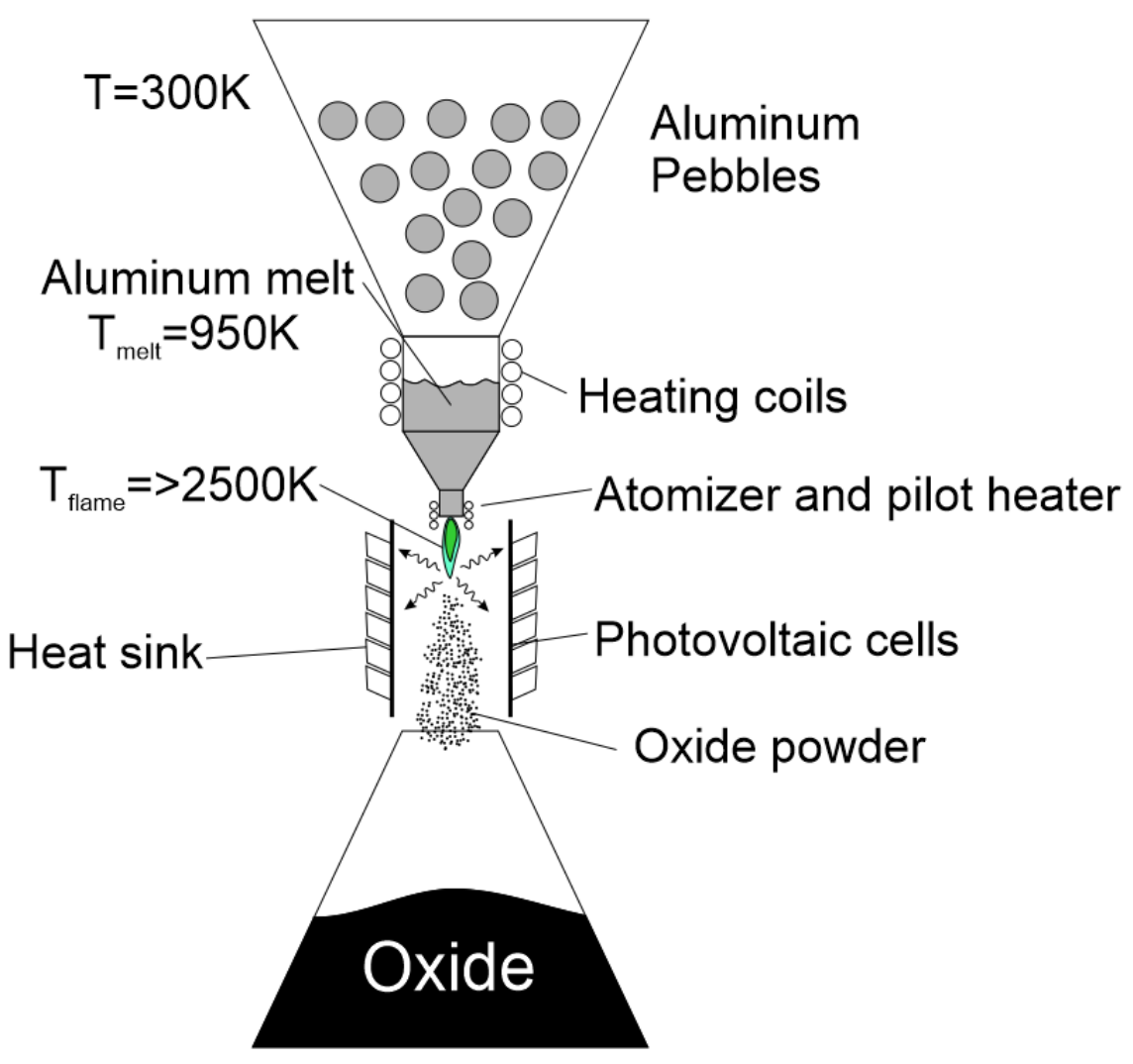


Particle generation and capture: In order to avoid transporting and storing powdered aluminum metal, it is useful to take advantage of the relatively low melting point of aluminum $(\sim 950 \mathrm{~K})$ to enable an atomizer to disperse particles to the proper size, where they can then rapidly combust. Atomizers, of which many types exist, are commonly used in the production of metal powders in spray forming processes. An additional heater can be added at the end of the atomizer to kick-start the reaction. It has been shown in previous research that (in the proper concentrations) aluminum particles will continuously burn once ignited [7]. Once the particles combust, the resulting oxide can be collected in a second container, and transported back to the aluminum smelting facility, where electrical power can be used to convert the oxide back to metal. Particle collection can be done via filtration or by other separation techniques. Finally, the NOx pollutants from aluminum combustion have yet to be quantified, but NOx reduction systems are common and can be used to reduce the NOx levels to acceptable values. A schematic of the system is shown in Figure 1.

Technoeconomic Analysis, fuel: A rough estimate of the cost of aluminum as a fuel is given in table 1, compared to other kinds of zero carbon fuel sources. This calculation makes a few key assumptions:

1. Cost of aluminum is $\$ 1.8 / \mathrm{kg}$, a rough estimate based on market prices.

2. The cost of alumina, and carbon anodes constitute $52 \%$ of the market price and are neglected, as these will be re-usable [12].

3. Hydrogen and ammonia are assumed to be produced from steam methane reforming and do not include the costs of carbon capture and storage. Ammonia costs include estimates of liquification costs at $\$ 0.13 / \mathrm{kg}$.

Table 1: Technoeconomic Analysis of Aluminum Combustion

\begin{tabular}{llllll}
\hline & $\begin{array}{l}\text { Fuel cost } \\
(\$ / \mathrm{kg})\end{array}$ & $\begin{array}{l}\text { Gravimetric } \\
\text { Energy Density } \\
(\mathrm{MJ} / \mathrm{kg})\end{array}$ & $\begin{array}{l}\text { Volumetric } \\
\text { Energy Density } \\
(\mathrm{MJ} / \mathrm{L})\end{array}$ & $\begin{array}{l}\text { Assumed Engine } \\
\text { Efficiency }\end{array}$ & $\begin{array}{l}\text { Energy } \\
\text { cost (\$/GJ) }\end{array}$ \\
\hline $\begin{array}{l}\text { Liquid } \\
\begin{array}{l}\text { Hydrogen } \\
\text { Compressed }\end{array}\end{array}$ & 4.0 & 141 & 8 & $45 \%$ & 63 \\
$\begin{array}{l}\text { hydrogen } \\
\text { Ammonia }\end{array}$ & 0.53 & 141 & 1.5 & $45 \%$ & 24 \\
$\begin{array}{l}\text { Aluminum } \\
\text { Diesel }\end{array}$ & 0.88 & 31 & 11.5 & $45 \%$ & 62 \\
\hline
\end{tabular}

Table 1 shows that under these assumptions, only compressed hydrogen is competitive with diesel in terms of cost. However, as mentioned before, the low energy density of the compressed hydrogen fuel is low, and therefore unsuitable for many long-range transportation applications. Furthermore, if truly $\mathrm{CO} 2$ free hydrogen and ammonia would be included in this list, which would be produced via electrolysis or using carbon capture, the cost would likely be significantly higher for the hydrogen and ammonia options (Also interesting is the retail price of hydrogen for passenger vehicles in California is currently well over $10 \$ / \mathrm{kg}$ [13]). While these calculations are filled with speculations, they show that an aluminum-based combustion system may be cost competitive with other zero-carbon fuel sources. Many thanks to Richard Randall and Eddie Sun for their contributions to this analysis.

Technoeconomic Analysis, TVP system: Previous work has already been done to estimate the cost of a TVP system for grid scale storage applications [14]. In this work, the PV cells themselves constitute the largest portion of the cost of the power costs, and the production costs are assumed to be $10 \mathrm{k} \$ / \mathrm{m}^{2}$ of PV cells, an estimate which comes from the cost of GaAs production (the authors note 
that silicon PV production costs are significantly lower, at $\sim 50 \$ / \mathrm{m}^{2}$ ). A key technical metric for a TPV system is the power density of the PV cells. In the work cited, the assumed power density of the PV cells is $100 \mathrm{~kW} / \mathrm{m}^{2}$. This value is consistent with many concentrated solar power systems [15]. The higher this number, the lower the overall cost of power of the system will be, as less total area will be required for the system. As an interesting side note, if these power densities can be achieved, they will be roughly a factor of 20 times greater than the areal power densities of fuel cells. The PV cells therefore contribute $0.1 \$ / \mathrm{W}$ of cost to the system. Other additional costs of the system are found in ref [14].

The final cost of power of the system is computed to be $0.34 \$ / \mathrm{W}$, which is comparable to gas turbine power costs at $0.60 \$ / \mathrm{W}$ (2015 data) [16]. However, academic cost modeling tends to underestimate the cost of new technologies, so significantly more work will need to be done in order to truly estimate the cost of a full TPV system.

\section{References:}

1. Direct combustion of recyclable metal fuels for zero-carbon heat and power. 2015. http://dx.doi.org/10.1016/j.apenergy.2015.09.037

2. Aluminum and its role as a recyclable, sustainable carrier of renewable energy. 2020. https://doi.org/10.1016/j.apenergy.2020.115112

3. World first: Dutch brewery burns iron as a clean, recyclable fuel. 2020. https://newatlas.com/energy/bavarian-brewery-carbon-free-renewable-iron-fuel/

4. World Mineral Production: 2014-2018. 2020.

https://www2.bgs.ac.uk/mineralsuk/download/world_statistics/2010s/WMP_2014_2018.pdf

5. Apple buys first-ever carbon-free aluminum from Alcoa-Rio Tinto venture. 2019 https://www.reuters.com/article/ctech-us-apple-aluminum-idCAKBN1Y91RQ-OCATC

6. Characterization of different grades of aluminum anodes for aluminum/ air batteries. 1997. https://doi.org/10.1016/S0378-7753(97)02473-7

7. Determination of aluminum-air burning velocities using PIV and Laser sheet tomography. 2019. https://doi.org/10.1016/i.proci.2018.07.013

8. Combustion characteristics of pure aluminum and aluminum alloys powders. 2019 https://doi.org/10.1016/i.jlp.2020.104270

9. Dense energy carrier assessment of four combustible metal powders. 2018. https://doi.org/10.1016/j.seta.2018.09.003

10. Ultraefficient thermophotovoltaic power conversion by band-edge spectral filtering. 2019. https://doi.org/10.1073/pnas.1903001116

11. The Brayton Battery; Modular, Solid-State Thermal Energy | Prof. R. Laughlin, A. Ponec| StorageX. 2020 https://www.youtube.com/watch?v=3ejHRC7rmZc

12. Analysis of production costs in the aluminium smelting industry. 2012. https://www.scribd.com/fullscreen/106098247?access key=key24075j4emr214y1vlcst\&allow share=true\&escape=false\&view mode=scroll

13. Joint Agency Staff Reporton Assembly Bill 8: 2019 Annual Assessment of Time and Cost Needed to Attain 100 Hydrogen Refueling Stations in California. 2019. https://ww2.energy.ca.gov/2019publications/CEC-600-2019-039/CEC-600-2019-039.pdf

14. Thermal energy grid storage using multi-junction photovoltaics. 2019. https://doi.org/10.1039/C8EE02341G

15. Opportunities and Challenges for Development of a Mature Concentrating Photovoltaic Power Industry. 2012 https://www.nrel.gov/docs/fy13osti/43208.pdf

16. Construction costs for most power plant types have fallen in recent years. 2017 . https://www.eia.gov/todayinenergy/detail.php?id=31912 